\title{
Regulation of collagen dissolution in the human cervix by oestradiol-17 $\beta$ and progesterone
}

\author{
R. M. Wallis and K. Hillier \\ Clinical Pharmacology, University of Southampton, Medical \& Biological Sciences Building, \\ Bassett Crescent East, Southampton SO9 3TU, U.K.
}

\begin{abstract}
Summary. Explants of non-pregnant human cervix in culture for 10 days spontaneously synthesized collagenolytic enzymes which dissolved the collagen in the tissue, resulting in the release of hydroxyproline-containing peptides. Progesterone at $8 \times 10^{-7} \mathrm{M}$ and oestradiol-17 $\beta$ at $4 \times 10^{-6} \mathrm{M}$ reduced this breakdown by $50 \%$, but oestradiol-17 $\beta$ was only inhibitory if the tissue was maintained in an oestrogen-containing environment throughout the preparation of the tissue explants. We conclude that the connective tissue matrix of the human cervix is partly under hormonal control.
\end{abstract}

\section{Introduction}

The mechanisms by which the biochemical structure of the human cervix changes toward term and during labour resulting in its softening and dilatation are poorly understood. The largely collagenous nature and sparse regionally distributed smooth muscle of the human cervix (Danforth, 1954) make it necessary to explain the softening process in terms of connective tissue restructuring. The collagen in the non-pregnant human cervix appears as dense, interlacing fibrils bound by glycosaminoglycans (Danforth, Buckingham \& Roddick, 1960; Danforth et al., 1974). However, immediately after parturition the cervix has less collagen and glycoproteins, increased water content and glycosaminoglycans (primarily keratan sulphate) (Danforth et al., 1974; Maillot, Stuhlsatz, Mohanaradhakrishnan \& Greiling, 1979).

The time course of the softening process in pregnancy and parturition has yet to be precisely determined. It has been shown that, in the post-partum human cervix, collagen solubility is increased and this solubility is associated with a breakdown of the collagen structure (Maillot \& Zimmerman, 1975; Kleissl, Van Der Rest, Naftolin, Glorieux \& DeLeon, 1978). In the rat cervix reduced collagen content has been equated with decreased tensile strength and enhanced distensibility (Zarrow \& Yochim, 1961) but this direct relationship has yet to be unequivocally demonstrated in human tissue. The reduction in tissue collagen content may be attained by enhanced dissolution and/or a reduction in collagen synthesis.

The collagen molecule consists of three polypeptide chains ( $\alpha$ chains) linked together by cross linkages to form a stable triple helix which is resistant to attack by most proteases. Collagenase is the only enzyme known to carry out the initial attack on the helical collagen under physiological conditions of $\mathrm{pH}$ and ionic strength. The fragments of the collagen molecule are then further degraded by proteases and by phagocytosis (Harris \& Krane, 1974).

Progesterone inhibits collagenase synthesis by explants of the involuting rat uterus (Jeffery, Coffey \& Eisen, 1971), and oestradiol abolishes collagenase production by explants of the non-pregnant rabbit uterus (Cartwright, Murphy, Sellers \& Reynolds, 1977). In the present study, we examined the viability of human cervical tissue in relatively long-term culture, its ability to maintain synthesis of collagenolytic enzymes and the effect of oestradiol-17 $\beta$ and progesterone on collagen dissolution. 


\section{Materials and Methods}

\section{Tissue collection and incubation}

Cervical tissue from 20 non-pregnant women was taken from the proximity of the internal os immediately after hysterectomy for benign gynaecological disease, and was placed in ice-cold Modified Minimum Essential Medium with Earle's salts (Flow Laboratories, Irvine, Scotland) containing 7.3 units penicillin $/ \mathrm{ml}$ and $4.4 \mu \mathrm{g}$ streptomycin $/ \mathrm{ml}$ (Glaxo, Greenford, Middlesex) and $2 \times 10^{-3} \mathrm{M}$-glutamine (Flow Laboratories) (EMEM). The outer $5 \mathrm{~mm}$ of the cervix was discarded and tissue explants $<1 \mathrm{~mm}$ thick and about $60 \mathrm{mg}$ in weight were prepared (30-40 explants were obtained from each patient). Each Petri dish consisted of 3 explants incubated on stainless-steel grids at the interface of $3 \mathrm{ml}$ EMEM and $5 \%$ carbon dioxide in oxygen at $37^{\circ} \mathrm{C}$ for a period of 10 days. Progesterone and oestradiol-17 $\beta$ (Sigma, London) were added in ethanol (final concentration $0.5 \%$ ); vehicle alone was added to controls. The time from removal of tissue to addition of test hormones and incubation at $37^{\circ} \mathrm{C}$ was about $1 \frac{1}{2} \mathrm{~h}$. Some experiments were carried out to determine if the absence of steroids during the preparative period altered the subseanent responsiveness to that hormone when the tissue was cultured. Tissue was halved within 3 min of hysterectomy; one segment was immediately placed in EMEM alone and the other in EMEM containing the hormones being investigated at a concentrations of $10^{-7} \mathrm{M}$. The responses of both halves to higher concentrations of steroids were then compared.

\section{Assay}

Incubation medium was harvested every 2 nd day and stored at $-20^{\circ} \mathrm{C}$ until assayed. An aliquot of incubation medium was hydrolysed with $6 \mathrm{~N}$-hydrochloric acid for $16 \mathrm{~h}$ at $100^{\circ} \mathrm{C}$, neutralized and assayed for hydroxyproline by using the overnight method of Bergman \& Loxley (1963) scaled down to utilize $200 \mu \mathrm{l}$ of the neutralized hydrolysate. This assay system can detect $9 \times 10^{-6} \mathrm{M}$-hydroxyproline in $1 \mathrm{ml}$ of the original incubation medium. The inter- and intra-assay coefficients of variation were $8 \%(n=6)$ and $10 \%(n=10)$ respectively.

Experiments were initially carried out to determine the optimum conditions for collagen dissolution. Changing the incubation medium every 2 nd day of culture rather than daily did not affect collagen dissolution (measured by the appearance of hydroxyproline in the incubation medium), but changing the incubation medium every 3rd day significantly depressed hydroxyproline levels. Ethanol ( $0.5 \%)$ had no effect.

Routinely, tissue was cultured for 10 days and hydroxyproline assayed in the incubation medium harvested from Day 5 until Day 10, the period during which the hormone-induced changes are most readily observed; the results are expressed in terms of total hydroxyproline ( $\mathrm{nmol} / 100 \mathrm{mg}$ initial wet weight of tissue) production during Days 5-10 of culture compared to that for control cultures which were always carried out in parallel. In experiments set up to correlate tissue hydroxyproline loss with the appearance of hydroxyproline in the medium, tissues were cultured for up to 20 days. The tissue was hydrolysed with $1 \mathrm{ml} 6 \mathrm{~N}-\mathrm{HCl}$ overnight at $100^{\circ} \mathrm{C}$. The hydrolysate was centrifuged to remove the carbon residue, neutralized and diluted in citrate buffer $\mathrm{pH} 6(1: 20 \mathrm{v} / \mathrm{v})$ before assay for hydroxyproline. The percentage hydroxyproline lost was estimated by comparing the hydroxyproline content of explants before and after culture.

\section{Histological examination of cervix explants}

Cervix explants were fixed in Heidenhain's SUSA fixative overnight, dehydrated and embedded in paraffin wax (Culling, 1963). Sections $7 \mu \mathrm{m}$ in thickness were prepared and stained with haematoxylin and eosin. 


\section{Results}

Hydroxyproline-containing peptides were released into the incubation medium during culture of human cervical tissue (Text-fig. 1) and this accumulation was therefore used as an index of collagen dissolution. Determination of the tissue hydroxyproline content before and after culture and comparison with amounts of hydroxyproline in the incubation medium after hydrolysis showed that the hydroxyproline concentration in the medium could be correlated with a loss of hydroxyproline from the explants. Typically, cervix explants lost approximately $10 \%$ of the initial hydroxyproline content during the first 10 days of culture but nearly $80 \%$ after 20 days (Text-fig. 1).

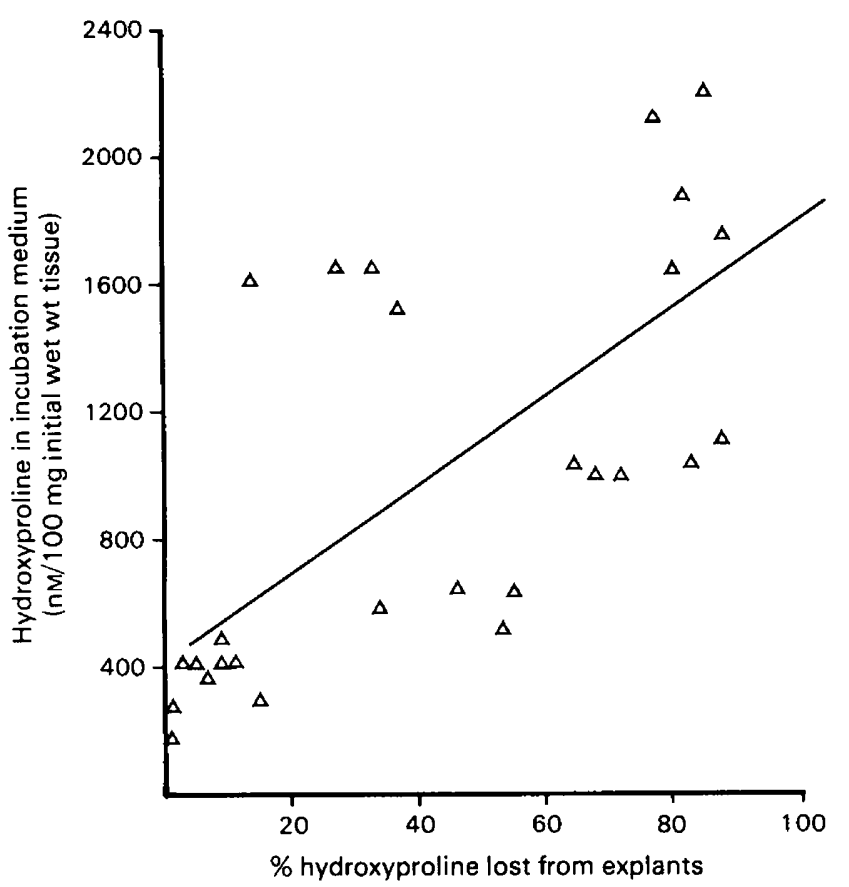

Text-fig. 1. Correlation between the percentage loss of tissue hydroxyproline-containing peptides from non-pregnant human cervix explants during culture for 20 days and the appearance of hydroxyproline in the incubation medium assayed after hydrolysis $(n=27)$. The correlation line is described by the equation $y=13 x+462 \cdot 9, r=0.65, P<0.001$.

Histological examination of the tissue before culture showed the collagen as dense, interlacing fibres associated with spindle-shaped stroma cells. Epithelia present in the explants were columnar, with the tissue matrix below the epithelia appearing less dense and regular than the deeper stroma. The most significant progressive change in the explants was the flattening of the epithelia which became cuboidal by Days 6-8 of culture. However, even after 10 days in culture all the epithelial membranes were intact and still attached to the stromal tissue. The deep stromal tissue showed no significant change during culture although by Days 8-10 cell density appeared to increase in association with the subjective impression of disaggregation of the collagen matrix. There was no evidence of any necrotic cells throughout the culture period. 


\section{Effects of oestrogens}

In initial experiments, tissue collected into the EMEM without hormones did not respond to the subsequent addition of oestradiol- $17 \beta$ after $1 \frac{1}{2} \mathrm{~h}$. However, when the tissue was placed immediately after collection into EMEM containing $10^{-7} \mathrm{M}$-oestradiol-17 $\beta$, subsequent hormone caused a concentration-related inhibition of collagen breakdown (extrapolation of these data indicated $50 \%$ inhibition at $4 \times 10^{-6} \mathrm{M}$ ) (Table 1). Concentrations of $1 \times 10^{-6}$ and $5 \times 10^{-6}$ M-oestradiol- $17 \beta$ were soluble in EMEM containing $0.5 \%$ ethanol at $37^{\circ} \mathrm{C}$, but that of $1 \times 10^{-5} \mathrm{M}$ approached the limit of solubility and slight turbidity of the solution was noted. However, the biological effect of oestradiol at this concentration followed the pattern seen with lower doses, the lipid solubility ensuring adequate tissue uptake.

Table 1. The effect of immediate or delayed addition of oestradiol-17 $\beta$ on the accumulation of hydroxyproline-containing peptides in culture medium on

Days 5-10 of human cervical explants maintained in culture for 10 days

\begin{tabular}{|c|c|c|}
\hline \multirow[b]{2}{*}{ Treatment } & \multicolumn{2}{|c|}{$\begin{array}{c}\text { Total hydroxyproline (nM/100 mg initial } \\
\text { wet wt of tissue) }\end{array}$} \\
\hline & EMEM alone & $\begin{array}{c}\text { EMEM + oestradiol-17 } \beta \\
\left(1 \times 10^{7} \mathrm{M}\right)\end{array}$ \\
\hline 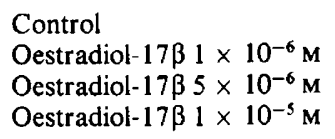 & $\begin{array}{l}320.9 \pm 44.0(10) \\
244.4 \pm 52.5(6) \\
262.8 \pm 60.0(6) \\
212.6 \pm 44.5(9)\end{array}$ & $\begin{array}{l}258.9 \pm 35.6(9) \\
157.3 \pm 19.9(6)^{*} \\
143.3 \pm 10.0(6)^{*} \\
70.4 \pm 10.3(9)^{* *}\end{array}$ \\
\hline
\end{tabular}

Values are mean \pm s.e.m. for the no. of observations in parentheses.

Values significantly different from those in respective control experiments, ${ }^{*} P<0.05 ;{ }^{* *} P<0.001$ (Student's $t$ test).

Evidence that this is a receptor-mediated event was suggested by lack of effect of oestradiol-17 $\alpha\left(5 \times 10^{-7}\right.$ to $\left.5 \times 10^{-5} \mathrm{M}\right)$ and oestriol $\left(1 \times 10^{-7}\right.$ to $\left.5 \times 10^{-5} \mathrm{M}\right)$ (results not shown).

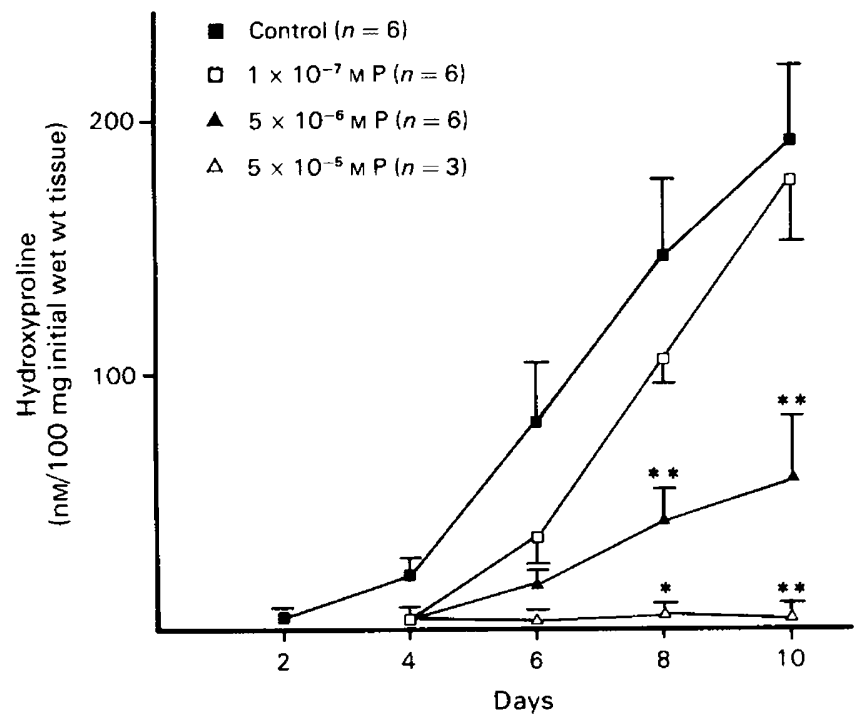

Text-fig. 2. Effect of increasing concentrations of progesterone $(P)$ on the appearance of hydroxyproline-containing peptides in the incubation medium of cultures of explants of non-pregnant human cervix. ${ }^{*} P<0.02 ;{ }^{* *} P<0.01$ compared with control values on that day (Student's $t$ test). 


\section{Effect of progesterone}

There was a concentration-related reduction in the accumulation of hydroxyprolinecontaining peptides in the culture medium $\left(50 \%\right.$ inhibition at $\left.8 \times 10^{-7} \mathrm{M}\right)$ (Text-fig. 2). There was no difference in the response to progesterone when tissue was collected into medium alone or medium containing $1 \times 10^{-7} \mathrm{M}$-progesterone immediately after removal at hysterectomy.

\section{Discussion}

The appearance of soluble hydroxyproline-containing peptides in the incubation medium is characteristic of collagenase-synthesizing explants. The time course for the collagen dissolution essentially follows that described for cultures of the involuting rat uterus (Jeffery et al., 1971) and the non-pregnant rabbit uterus (Cartwright et al., 1977), with the collagen breakdown being low over the first 4 days of culture. This initial delay in collagen dissolution may represent low levels of active collagenolytic enzymes as a result of the synthesis of a pro-enzyme (Vaes, 1972) or the concurrent synthesis of an enzyme inhibitor (Sellers, Cartwright, Murphy \& Reynolds, 1977).

The absence of any cellular necrosis after 10 days in culture eliminates the possibility that the appearance of hydroxyproline in the culture medium is related to necrosis. Moreover, the ability of oestradiol and progesterone to inhibit dissolution makes it highly unlikely that the observations are due to degenerative changes. The loss of collagen from the tissue was associated temporally with the appearance of hydroxyproline in the culture medium, suggesting that net collagen breakdown was being measured although diminished collagen synthesis may also have contributed.

The effect of steroid hormones on cervical collagen dissolution may be related to the ability of these hormones to diminish collagenase synthesis as shown in uterine tissue of rat (Jeffery $e t$ al., 1971) and rabbit (Cartwright et al., 1977). This action of progesterone may involve suppression of messenger RNA synthesis (Jeffery \& Koob, 1973). The inhibition of collagenase synthesis by progesterone has also been equated with retarded involution of the uterus in vivo (Halme \& Woessner, 1975).

Although there are no existing data on the effect of steroid hormones on the collagen content of the human cervix in vivo, the effect of progesterone in vitro may help to explain the results of Liggins, Grieves, Kendall \& Knox (1972) who showed that cervix softening in sheep treated with dexamethasone could be prevented by progesterone in doses too low to inhibit uterine contractility. Fitzpatrick (1977) also suggested that the degree of cervix softening induced in sheep by infusion of prostaglandin F-2 $\alpha$ was inversely related to peripheral progesterone concentrations. Although these observations are at variance with those of Stys, Clewell \& Meschia (1978), who showed that progesterone did not inhibit cervix softening in sheep at term, we suggest that the prevention of cervix softening observed in some studies following progesterone treatment is due to inhibition of the processes involved in collagen dissolution.

Our work indicates that if tissue is deprived of oestradiol-17 $\beta$ for about $1 \frac{1}{2} \mathrm{~h}$ then subsequent responsiveness to that hormone is lost. Peck, De Libero, Richards \& Clark (1973) have previously shown that in vitro the oestrogen receptors of the uterus are labile and are lost in the absence of oestrogen. Our findings suggest a similar effect in human cervix.

The inhibitory effect found with oestradiol- $17 \beta$ is more difficult to correlate with data from other sources. A similar action of oestradiol has been demonstrated for explants of non-pregnant rabbit uterus (Cartwright et al., 1977). In the rat in-vitro treatment of the post-partum involuting uterus with oestradiol-17 $\beta$ did not inhibit collagen dissolution (Jeffery et al., 1971), but treatment of animals with oestradiol-17 $\beta$ followed by subsequent examination of the collagen content of the uterus identified an inhibitory effect of the steroid on involution (Ryan \& Woessner, 1974; Woessner, 1979). The apparent discrepancy between the effects of oestrogens 
in vivo and in vitro may be explained by a 'labile' oestrogen receptor. For example, if Jeffrey et al. (1971) had maintained their rat uterine tissues in an oestrogen-containing environment throughout the preparation of their explants in culture, an inhibitory effect may have been observed as in the present study with human cervical tissue. However, the converse effect was found with non-pregnant ovariectomized rats. Treatment with oestradiol-17 $\beta$ or oestradiol-17 $\beta$ and relaxin induced a dispersal or separation of the collagen fibres (Leppi \& Kinnison, 1971). These observations may be explained in terms of changes in the glycosaminoglycans which may effect an increased susceptibility of the collagen to collagenolytic enzymes (Flint, 1972).

Oestrogens have been used clinically to soften the cervix, but the results are equivocal. Gordon \& Calder (1977) reported softening of the cervix with oestradiol-17 $\beta$ although other workers have reported negligible action (Thiery et al., 1978) or effective softening only with doses that also induce uterine stimulation (Craft \& Yovich, 1978); this indicates that the effect may be secondary to enhanced uterine contractility. We have never observed an increase in collagen dissolution with oestradiol treatment; significant inhibition was observed if the tissue was maintained in an oestrogen-containing environment. We, therefore, suggest that, if oestrogens are effective in softening an unripe cervix in vivo, this action may be mediated through mechanisms other than direct collagen dissolution, such as altered uterine contractility or glysosaminoglycans. In the human cervix the glycosaminoglycan composition, in particular hyaluronate and keratan sulphate, increases throughout pregnancy (Danforth et al., 1974; Maillot et al., 1979). These changes may alter collagen fibre organization (Borcherding et al., 1975 ) or the susceptibility to collagenolytic enzyme-induced breakdown (Flint, 1972).

If collagenolytic activity is a major prerequisite of cervix softening then it would be expected to increase during softening. Preliminary data in the rat suggest that an increase in enzyme activity is apparent during late pregnancy (R. M. Wallis \& K. Hillier, unpublished observations) and the observations of Kitamura, Ito, Mori \& Hirakawa (1979) for the human cervix during pregnancy would support this. We conclude that collagen dissolution in the human cervix is under hormonal control and that progesterone and oestradiol-17 $\beta$ are, at least in part, responsible for the structural integrity of the cervix.

We gratefully acknowledge the financial support of the Lalor Foundation, and the co-operation of the obstetric and theatre staff of Southampton General Hospital. We thank Dr J. Mitchell and Dr P. Thorogood, University of Southampton, for advice and practical help.

\section{References}

Bergman, I. \& Loxley, R. (1963) Two improved and simplified methods for the spectrophotometric determination of hydroxyproline. Analyt. Chem. 35, 1961-1965.

Borcherding, M.S., Blacik, L.T., Sittig, R.A., Bizzel, J.W., Breen, M. \& Weinstein, H.G. (1975) Proteoglycans and collagen fibre organization in human corneoscleral tissue. Expl Eye Res. 21, 59-70.

Cartwright, E., Murphy, G., Sellers, A. \& Reynolds, J. (1977) Collagenase activity from cultured rabbit uterus. Biochem. Soc. Trans. 5, 229-230.

Craft, I. \& Yovich, J. (1978) Oestradiol and induction of labour. Lancet ii, 208.

Culling, C.F.A. (Ed.) (1963) Handbook of Histopathological Techniques. Butterworth, London.

Danforth, D.N. (1954) The distribution and functional activity of the cervical musculature. Am. J. Obstet. Gynec. 68, 1261-1271.

Danforth, D.N., Buckingham, J. \& Roddick, J.W. (1960)
Connective tissue changes incident to cervical effacement. Am. J. Obstet. Gynec. 80, 939-944.

Danforth, D.N., Veis, A., Breen, M., Weinstein, H., Buckingham, J.C. \& Manalo, P. (1974) The effect of pregnancy and labour on the human cervix: changes in collagen, glycoproteins and glycosaminoglycans. Am. J. Obstet. Gynec. 120, 641-651.

Fitzpatrick, R. (1977) Dilation of the uterine cervix. In The Fetus and Birth (Ciba Fdn Symp. No. 47), pp. 31-47. Eds J. Knight \& M. O'Connor. Elsevier, Amsterdam.

Flint, M. (1972) Interrelationships of mucopolysaccharide and collagen in connective tissue remodelling. J. Embryol. exp. Morph. 27, 481-495.

Gordon, A.J. \& Calder, A.A. (1977) Oestradiol applied locally to ripen the unfavourable cervix. Lancet ii, 1319.

Halme, J. \& Woessner, J.F. (1975) Effect of progesterone on collagen breakdown and tissue col- 
lagenolytic activity in the involuting rat uterus. $J$. Endocr. 66, 357-362.

Harris, E. \& Krane, S. (1974) Collagenase. New Eng. J. Med. 291, 557-563.

Jeffery, J.J. \& Koob, T. (1973) Hormonal regulation of collagen catabolism in the uterus. Proc. $4 \mathrm{th}$ Int. Congr. Endocrinology, Amsterdam, pp. 1115-1121.

Jeffery, J.J., Coffey, R.J. \& Eisen, A.Z. (1971) Studies on uterine collagenase in tissue culture. 2. Effect of steroidal hormones on enzyme production. Biochem. Biophys. Acta 252, 143-149.

Kitamura, K., Ito, A., Mori, Y. \& Hirakawa, S. (1979) Changes in the human uterine cervical collagenase with specific reference to cervical ripening. Biochem. Med. 22, 332-338.

Kleissl, H., Van Der Rest, M., Naftolin, F., Glorieux, F. \& DeLeon, A. (1978) Collagen changes in the human uterine cervix at parturition. Am.J. Obstet. Gynec. 130, 748-753.

Leppi, J. \& Kinnison, P. (1971) The connective tissue ground substance in the mouse uterine cervix: an electron microscopic histochemical study. Anat. Rec. 170, 97-118.

Liggins, G., Grieves, S., Kendall, J. \& Knox, B. (1972) The physiological roles of progesterone, oestradiol$17 \beta$ and $\mathrm{PGF}_{2 \alpha}$ in the control of ovine parturition. $J$. Reprod. Fert., Suppl. 16, 85-103.

Maillot, K. \& Zimmerman, B.K. (1975) The solubility of collagen of the uterine cervix during pregnancy and labour. Arch. Gynak. 220, 275-280.

Maillot, K., Stuhlsatz, H.W., Mohanaradhakrishnan, V. \& Greiling, H. (1979) Changes in glycosamino- glycan distribution pattern in human uterine cervix during pregnancy and labour. Am. J. Obstet. Gynec. 135, 503-506.

Peck, E.J., De Libero, J., Richards, R. \& Clark, J.H. (1973) Instability of the uterine oestradiol receptor under in vitro conditions Biochemistry, N.Y. 12, 4603-4608.

Ryan, J.N. \& Woessner, J.F. (1974) Oestradiol inhibition of collagenase role in uterine involution. Nature, Lond. 248, 526-528.

Sellers, A., Cartwright, E., Murphy, G. \& Reynolds, J.J. (1977) An inhibitor of mammalian collagenase from foetal rabbit bone in culture. Biochem. Soc. Trans. 5, 227-229.

Stys, S., Clewell, W. \& Meschia, G. (1978) Changes in cervical compliance at parturition independent of uterine activity. Am.J. Obstet. Gynec. 130, 414-418.

Thiery, M., De Gezelle, H., Vankets, H., Voorhoot, K., Verheugen, C., Smis, B., Grerris, J. \& Martens, G. (1978) Extra-amniotic oestrogens for the unfavourable cervix. Lancet ii, 835-836.

Vaes, G. (1972) The release of collagenase as an inactive proenzyme by bone explants in culture. Biochem. $J$. 126, 275-289.

Woessner, F. (1979) Total, latent and active collagenase during the course of postpartum involution of the rat uterus. Effect of oestradiol. Biochem. J. 180, 95-102.

Zarrow, M.X. \& Yochim, J. (1961) Dilation of the uterine cervix of the rat and accompanying changes during the estrous cycle, pregnancy and following treatment with estradiol, progesterone and relaxin. Endocrinology 69, 292-304.

Received 16 June 1980 